\title{
In vitro synergism of magnolol and honokiol in combination with antibacterial agents against clinical isolates of methicillin-resistant Staphylococcus aureus (MRSA)
}

\author{
Guo-Ying Zuo ${ }^{1 *}$, Xin-Juan Zhang ${ }^{1,2}$, Jun Han ${ }^{3^{*}}$, Yu-Qing Li ${ }^{3}$ and Gen-Chun Wang ${ }^{1}$
}

\begin{abstract}
Background: Methicillin-resistant Staphylococcus aureus (MRSA) is a problematic pathogen posing a serious therapeutic challenge in the clinic. It is often multidrug-resistant (MDR) to conventional classes of antibacterial agents and there is an urgent need to develop new agents or strategies for treatment. Magnolol (ML) and honokiol $(\mathrm{HL})$ are two naturally occurring diallylbiphenols which have been reported to show inhibition of MRSA. In this study their synergistic effects with antibacterial agents were further evaluated via checkerboard and time-kill assays.

Methods: The susceptibility spectrum of clinical MRSA strains was tested by the disk diffusion method. The minimal inhibitory concentrations (MICs) and minimal bactericidal concentrations (MBCs) of ML and HL were assayed by broth microdilution. The synergy was evaluated through checkerboard microdilution and time-killing experiments.

Results: ML and HL showed similar activity against both MSSA and MRSA with MIC/MBC at $16 \sim 64 \mathrm{mg} / \mathrm{L}$, with potency similar to amikacin (AMK) and gentamicin (GEN). When they were used in combination with conventional antibacterial agents, they showed bacteriostatic synergy with FICls between $0.25 \sim 0.5$, leading to the combined MICs decreasing to as low as $1 \sim 2$ and $1 \sim 16 \mathrm{mg} / \mathrm{L}$ for $\mathrm{ML}(\mathrm{HL})$ and the agents, respectively. $\mathrm{MIC}_{50}$ of the combinations decreased from $16 \mathrm{mg} / \mathrm{L}$ to $1 \sim 4 \mathrm{mg} / \mathrm{L}$ for $\mathrm{ML}(\mathrm{HL})$ and $8 \sim 128 \mathrm{mg} / \mathrm{L}$ to $2 \sim 64 \mathrm{mg} / \mathrm{L}$ for the antibacterial agents, which exhibited a broad spectrum of synergistic action with aminoglycosides (AMK, etilmicin (ETM) and GEN), floroquinolones (levofloxacin (LEV), ciprofloxacin and norfloxacin), fosfomycin (FOS) and piperacillin. The times of dilution (TOD, the extent of decreasing in MIC value) were determined up to 16 for the combined MIC. A more significant synergy after combining was determined as $M L(H L)$ with AMK, ETM, GEN and FOS. ML (HL) combined with antibacterial agents did not show antagonistic effects on any of the ten MRSA strains. Reversal effects of MRSA resistance to AMK and GEN by ML and HL were also observed, respectively. All the combinations also showed better dynamic bactericidal activity against MRSA than any of single ML (HL) or the agents at $24 \mathrm{~h}$ incubation. The more significant synergy of combinations were determined as $H L(M L)+E T M, H L+L E V$ and $\mathrm{HL}+\mathrm{AMK}$ (GEN or FOS), with $\Delta \mathrm{LC}_{24}$ of $2.02 \sim 2.25$.
\end{abstract}

Conclusion: $\mathrm{ML}$ and $\mathrm{HL}$ showed synergistic potentiation of antibacterial agents against clinical isolates of MRSA and warrant further pharmacological investigation.

Keywords: Magnolol, Honokiol, MRSA, Synergy, Antibacterial agent

\footnotetext{
*Correspondence: zuoguoying@263.net; hanzjn@126.com

${ }^{1}$ Research Center for Natural Medicines, Kunming General Hospital of

Chengdu Military Command, Kunming 650032, China

${ }^{3}$ School of Basic Medical Sciences, Yunnan Traditional Chinese Medical

College, Kunming 650500, China

Full list of author information is available at the end of the article
}

C Biomed Central (c) 2015 Zuo et al. Open Access This article is distributed under the terms of the Creative Commons Attribution 4.0 International License (http://creativecommons.org/licenses/by/4.0/), which permits unrestricted use, distribution, and reproduction in any medium, provided you give appropriate credit to the original author(s) and the source, provide a link to the Creative Commons license, and indicate if changes were made. The Creative Commons Public Domain Dedication waiver (http://creativecommons.org/publicdomain/zero/1.0/) applies to the data made available in this article, unless otherwise stated. 


\section{Background}

The opportunistic pathogen Staphylococcus aureus (SA) is a leading cause of bacterial infections of people, causing a broad spectrum of pathology ranging from common skin infections to deep-seated fatal disease [1] Antibiotic treatment of SA has once contributed greatly to human health for decades. However, due to long, wide and irrational applications of antibacterial agents in treatments in various fields other than in the clinic, methicillin-resistant Staphylococcus aureus (MRSA) has evolved as a problematic pathogen and has posed a serious therapeutic challenge in clinic $[1,2]$. Nowadays, MRSA infections can be monitored both in hospitals [healthcare-acquired /associated (HA) MRSA] and community [community-acquired/associated (CA) MRSA]. The livestock-associated MRSA [(LA) MRSA] has also occurred [3]. MRSA is able to produce resistance to nearly all common classes of antibiotics including $\beta$ lactams, aminoglycosides, macrolides, tetracyclines and quinolones, and even the vancomycin-resistant $S$. aureus (VRSA) has also been reported [4]. The decreasing effectiveness of conventional drugs is continuously haunting both clinicians and drug researchers, and the critical shortage of new antibiotics in development against MRSA and other multidrug-resistant bacteria is of great concern worldwide. New targets with novel strategy of therapy and mechanism of action for development of antibacterial agents against MRSA are urgently needed [5].

Plant natural resources have been demonstrated to possess great chemical and biological diversities and promising findings of antibacterial phytochemicals which showed not only anti-MRSA activity alone, but also synergistic potentials when they were used in combination with conventional antibacterial agents against MRSA [6-10]. In recent years, we are devoting efforts to search for novel phytochemicals that showed synergy with conventional antibacterial agents against MRSA from medicinal plant sources, especially from the traditional Chinese medicines (TCM) [11-13]. We found two diallylbiphenols, i.e. magnolol (ML) and honokiol (HL) are such phytochemicals contained in the Chinese crude drug Hou-po, the stem or root bark of Magnolia officinalis Rehd. et Wils. (Magnoliaceae) [14].

Hou-po is an important species in TCM [14]. It has been traditionally used for respiration, digestion and infection related ailments like cough, diarrhea, and allergic rhinitis [14]. Modern pharmacological reports also demonstrated its antimicrobial, anti-inflammatory and analgesic, antianxiety and antidepressant, antitumor and anticoagulant effects as well as myocardial/cerebral ischemia protections [15]. ML and HL are two main phenolic constituents primarily isolated from Hou-po and also found in other Magnolia sp., together with other nonphenolic constituents such as alkaloids and essential oils [16-18]. The antimicrobial effects of Hou-po extracts on
Bacillus anthracis, S. aureus and other pathogens were found as early as six decades ago [19-21]. Previous reports on antimicrobial activities of ML and HL and their synthetic derivatives include antibacterial [22-31], antifungal [32-34], antiviral [35] and nemicidal [36] activities. Although their antibacterial activities against MRSA and vancomycin-resistant enterococci (VRE) have been reported [37, 38], their potential for combined action on conventional antibacterial agents against MRSA has not been studied. Only the synergy of honokiol with fluconazole against clinical isolates of azole-resistant Candida albicans [39], and synergistic effect of lysozyme on bactericidal activity of magnolol and honokiol against a cariogenic bacterium of Streptococcus mutans OMZ 176 [40] including their potentiation of the antitumor agents [41-46] were reported. In this paper, we will show the potential synergistic effects of ML and HL in combination with conventional antibacterial agents against clinical MRSA strains through the checkerboard and time-kill curve methods.

\section{Methods}

\section{Antimicrobial agents and disks}

The eight antibacterial agents, i.e. amikacin (AMK) (Jiangsu Wuzhong Pharmaceutical Group Co., Ltd., Suzhou, China); Etilmicin (ETM) (Wuxi Jimin kexin Shanhe Pharmaceutical Co., Ltd.); gentamicin (GEN) (Guangzhou Baiyunshan Tianxin Pharmaceutical Co., Ltd., Guangzhou, China); Piperacillin (PIP) (Harbin Pharmaceutical Group Co., Ltd., Harbin, China); Norfloxacin (NOR) and Ciprofloxacin (CIP) (Sichuan Kelun Pharmaceutical Co., Ltd., Chengdu, China); Levofloxacin (LEV) (Yangzhijiang pharmaceutical Co., Ltd., Taizhou, China); Fosfomycin (FOS) (Northeast Pharmaceutical Group Co., Ltd., Shenyang, China). magnolol (ML) and honokiol (HL) (HPLC $>98 \%$; Xian Xiaocao Science and Technology Co., Ltd., Xian, China) (Fig. 1). Vancomycin (VAN) (Eli Lilly Japan K. K., Seishin Laboratories) was used as the positive control agent. Cefoxitin (cfx, $0.03 \mathrm{mg}$ ) and other antibiotic impregnated disks were purchased from Beijing Tiantan biological products Co., Ltd., China.

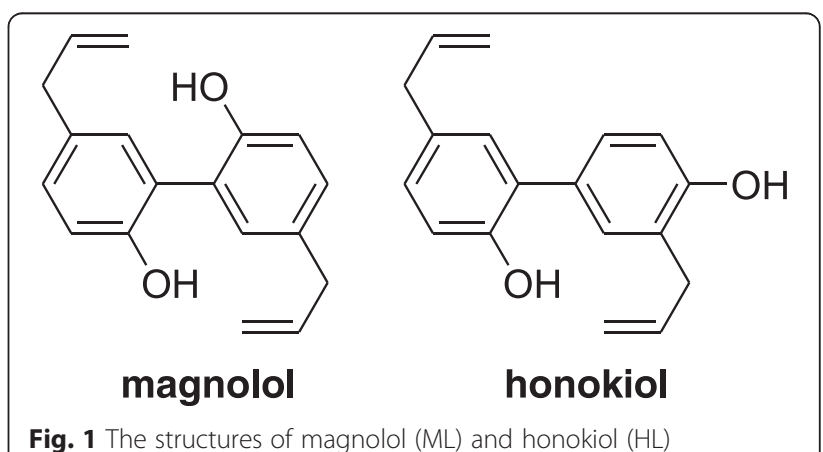




\section{Bacterial strains and media}

Ten MRSA strains (MRSA 01-10) were isolated and characterized from the infectious sputum sample of critically ill patients in $\mathrm{KGH}$ as previously reported [11-13]. The strains were determined with zone diameter $(\mathrm{ZD}) \leq 21$ $\mathrm{mm}$ against cefoxitin disk and the properties of susceptible $(\mathrm{S})$, intermediate $(\mathrm{I})$ and resistant $(\mathrm{R})$ to antibacterial agents were determined according to the ZD Interpretive Criteria of Table 2C in 2012 CLSI by comparison with the ZD of corresponding antibacterial agents (Table 1) [47]. The presence of mecA gene and SCCmec genotypes were determined by multiplex PCR methods in Kunming Institute of Virology, PLA, China, as previously reported [48]. The control strain for MRSA was $S$. aureus (ATCC 25923; methicillin-susceptible S. aureus (MSSA)) which was purchased from the Beijing Tiantan Pharmaceutical and Biological Technology Co., Ltd., China. Standard Mueller-Hinton agar and broth (MHA and MHB, Tianhe Microbial Agents Co., Hangzhou, China) were used as bacterial culture media. Colony counts were determined using MHA plates. MHB was used for quantitative susceptibility testing and dynamic time-kill experiments.

\section{Susceptibility testing}

The test of susceptibility spectrum of the ten clinical MRSA strains to conventional antibacterial agents was performed by disk diffusion test following the CLSI guideline $[47,49,50]$. MICs/MBCs of ML and HL were determined by standardized broth microdilution techniques with inoculums of $5 \times 10^{5} \mathrm{CFU} / \mathrm{mL}$ according to CLSI guidelines and incubated at $35{ }^{\circ} \mathrm{C}$ for $24 \mathrm{~h}$ [51-53]. The solvent used for dissolving the compounds and the antibiotics was MHB (or containing the final concentration of less than $5 \%$ of dimethyl sulphoxide).

\section{Synergy testing}

Potential interactions of ML and HL in combination with various antibiotics against MRSA were evaluated by determination of fractional inhibitory concentration indices (FICIs) and time-kill curves through using the checkerboard and dynamic time-kill methods as described previously $[12,13]$. The bacteriostatic interaction mode was judged by FICIs as follows: FICI $\leq 0.5$, synergy; $0.5<$ FICI $\leq$ 1 , additive; and $1<\mathrm{FICI}<2$, indifferent (or no effect) and FICI $\geq 2$, antagonism $[54,55]$. The bactericidal interaction mode was judged by the increased killing colony counts in $\log _{10} \mathrm{CFU} / \mathrm{mL}$ at $24 \mathrm{~h}$ incubation $\left(\Delta \mathrm{LC}_{24}\right)$ as follows: $\Delta \mathrm{LC}_{24} \geq 2 \log _{10} \mathrm{CFU} / \mathrm{mL}$, synergy; $\Delta \mathrm{LC}_{24}=1-2 \log _{10}$ $\mathrm{CFU} / \mathrm{mL}$, additive; $\Delta \mathrm{LC}_{24}= \pm 1 \log _{10} \mathrm{CFU} / \mathrm{mL}$, indifferent; $\Delta \mathrm{LC}_{24}>-1 \log _{10} \mathrm{CFU} / \mathrm{mL}$, antagonism; where the $\Delta \mathrm{LC}_{24}$ was calculated through the killing by a combination $\left(\mathrm{LC}_{24}(\mathrm{co}).\right)$ deducting that by the most active single drug $\left(\mathrm{LC}_{24}(\mathrm{si}).\right)$ in the combination, i.e. $\Delta \mathrm{LC}_{24}=\mathrm{LC}_{24}$ (co.) $\mathrm{LC}_{24}$ (si.) [56].

\section{Statistical analysis}

All the experiments were performed in triplicate. Data are expressed as the mean \pm standard error. Statistical analyses were performed using the Statistical Package for the Social Sciences (SPSS 20.0) software (SPSS Inc., Chicago, IL, USA). Data were analysed by KruskalWallis test and the significant differences between groups were analysed by Dunnett's test. Statistical significance was accepted at a level of $\mathrm{p}<0.01$.

\section{Results}

Antimicrobial effects of $M L$ and $H L$

The MICs/MBCs of ML, HL and eight conventional antibacterial agents alone against MSSA and MRSA are shown in Table 2. As a whole, ML and HL appeared as two moderate bactericidal agents against both MSSA

Table 1 Resistance spectrum of the ten clinical isolates of MRSA strains

\begin{tabular}{|c|c|c|c|}
\hline Strain & Resistant & Intermediate & Susceptible \\
\hline MRSA 008 & PEN, AMP, OXA, CFZ, CfX, P/T, ERY, AZM, CIP, LEV, NOR, CLI & & VAN, LZD, TEl \\
\hline MRSA 082 & PEN, AMP, OXA, CFZ, CfX, FUR, CPZ/S, P/T, ERY, AZM, CIA, CIP, LEV, NOR, CLI, RIF & FOS & VAN, LZD, TEl \\
\hline MRSA 098 & PEN, AMP, OXA, CFZ, Cfx, FUR, CPZ/S, P/T, ERY, AZM, CIP, LEV, NOR, CLI, RIF & & VAN, LZD, TEl \\
\hline MRSA 111 & PEN, AMP, OXA, CFZ, Cfx, FUR, CPZ/S, P/T, ERY, AZM, CIP, LEV, NOR, CLI, RIF & & VAN, LZD, TEI \\
\hline MRSA 135 & PEN, AMP, OXA, CFZ, Cfx, FUR, CPZ/S, P/T, ERY, AZM, CIP, LEV, NOR, CLI, RIF & & VAN, LZD, TEI, FOS \\
\hline MRSA 144 & PEN, AMP, OXA, CFZ, CfX, FUR, CPZ/S, P/T, ERY, AZM, CIP, LEV, NOR, CLI, RIF & & VAN, LZD, TEI \\
\hline MRSA 166 & PEN, AMP, OXA, CFZ, Cfx, FUR, CPZ/S, P/T, ERY, AZM, CIP, LEV, NOR, CLI, RIF, P/T & & VAN, LZD, TEI, FOS \\
\hline MRSA 187 & PEN, AMP, OXA, CFZ, Cfx, FUR, CPZ/S, P/T, ERY, AZM, CIP, LEV, NOR, CLI, RIF & & VAN, LZD, TEI, FOS \\
\hline MRSA 189 & PEN, AMP, OXA, CFZ, Cfx, FUR, CPZ/S, P/T, ERY, AZM, CIP, LEV, NOR, CLI, RIF & & VAN, LZD, TEI, FOS \\
\hline MRSA 321 & PEN, AMP, OXA, CFZ, CfX, FUR, P/T, ERY, AZM, CIP, LEV, NOR, CLI, CPZ/S, RIF & GAT, CTH, FOS & VAN \\
\hline
\end{tabular}

PEN Penicillin, AMP Ampicillin, OXA Oxacillin, CFZ Cefazolin, Cfx Cefoxitin, FUR Cefuroxime, CTH Cefathiamidine, CPZ/S Cefoperazone/sulbactam, P/T Piperacillin/tazobactam, ERY Erythromycin, AZM Azithromycin, CIP Ciprofloxacin, GAT Gatifloxacin, LEV Levofloxacin, CLI clindamycin, RIF Rifampicin, CLA Clarithromycin, FOS Fosfomycin, LZD Linezolid, TEI Teicoplanin, VAN Vancomycin 
Table 2 MICs/MBCs (mg/L) of magnolol (ML), honokiol $(\mathrm{HL})$ and conventional antibacterial agents against MSSA and the ten MRSA strains ${ }^{\mathrm{a}}$

\begin{tabular}{lllll}
\hline Agent $^{\mathrm{b}}$ & MSSA & \multicolumn{3}{l}{ MRSA $(n=10)$} \\
\cline { 3 - 5 } & & Range & $50 \%^{\mathrm{c}}$ & $90 \%^{\mathrm{d}}$ \\
\hline ML $^{*}$ & $32 / 32$ & $8 \sim 64^{*} / 16 \sim 128$ & $16 / 16$ & $64 / 64$ \\
$\mathrm{HL}^{*}$ & $16 / 32$ & $16 \sim 32^{*} / 16 \sim 64$ & $16 / 64$ & $32 / 64$ \\
ETM & $8 / 8$ & $4 \sim 16 / 8 \sim 32$ & $8 / 8$ & $16 / 16$ \\
AMK & $16 / 32$ & $32 \sim 128^{*} / 64 \sim 256$ & $64 / 128$ & $64 / 256$ \\
GEN & $16 / 32$ & $16 \sim 128 * / 64 \sim 256$ & $64 / 128$ & $64 / 128$ \\
LEV & $16 / 32$ & $128 \sim 256 / 256 \sim 512$ & $128 / 512$ & $256 / 512$ \\
CIP & $32 / 64$ & $256 \sim 512 / 256 \sim 1024$ & $256 / 512$ & $512 / 1024$ \\
NOR & $32 / 64$ & $256 \sim 512 / 256 \sim 1024$ & $256 / 512$ & $512 / 1024$ \\
PIP & $64 / 64$ & $128 \sim 256 / 256 \sim 512$ & $128 / 256$ & $256 / 512$ \\
FOS & $64 / 128$ & $128 \sim 256 / 256 \sim 512$ & $128 / 512$ & $256 / 512$ \\
VAN & $1 / 1$ & $2 / 2$ & $2 / 2$ & $2 / 2$
\end{tabular}

${ }^{a}$ MSSA Methicillin-susceptible Staphylococcus aureus (ATCC25923), MRSA Methicillin-resistant Staphylococcus aureus

${ }^{b}$ ML Magnolol, HL Honokiol, AMK Amikacin, ETM Etilmicin, GEN Gentamicin, PIP Piperacillin, CIP Ciprofloxacin, LEV Levofloxacin, FOS Fosfomycin, NOR Norfloxacin, VAN Vancomycin

${ }^{c_{50}} \%=\mathrm{MIC}_{50} / \mathrm{MBC}_{50}$, i.e. the minimal inhibitory and bactericidal

concentrations required to inhibit and kill $50 \%$ of the strains, respectively ${ }^{\mathrm{b}_{9}} 90 \%=\mathrm{MIC}_{90} / \mathrm{MBC}_{90}$, i.e. the minimal inhibitory and bactericidal concentrations required to inhibit and kill $90 \%$ of the strains, respectively ${ }^{*} p>0.01$

and MRSA. The two compounds showed varied MIC/ MBC of $16 \sim 64 \mathrm{mg} / \mathrm{L}$ against MSSA as most of the tested antibacterial agents, but they showed more potent activity than these agents against MRSA, with $\mathrm{MIC}_{90} /$ $\mathrm{MBC}_{90}$ of $64 / 64$ and $32 / 64 \mathrm{mg} / \mathrm{L}$, respectively. HL showed the same activity as AMK, GEN and LEV with MIC/MBC of 16/32 mg/L against MSSA. The antiMRSA potency of ML, HL and the eight agents followed the order of VAN $>$ ETM $>\mathrm{HL}>\mathrm{ML}>\mathrm{GEN}>\mathrm{AMK}>$ LEV (PIP, FOS) > CIP (NOR) judged by the values of $\mathrm{MIC}_{90} / \mathrm{MBC}_{90}$. Therefore, the antibacterial activity of the two compounds all showed more potent against MRSA than most of the conventional antibacterial agents with the exception of ETM and VAN (Table 2).

\section{Synergy of $M L$ and $H L$ in combination with antibacterial agents against MRSA}

Table 3 shows the different degree of synergistic interactions of ML and HL in combination with the eight antibacterial agents against the ten clinical MRSA isolates. There are three to ten MRSA strains that showed synergy with FICIs between $0.25 \sim 0.5$, leading to the combined MICs decreasing to as low as $1 \sim 2$ and $1 \sim 16 \mathrm{mg} / \mathrm{L}$ for ML (HL) and the agents, respectively. $\mathrm{MIC}_{50}$ of the combinations decreased from $16 \mathrm{mg} / \mathrm{L}$ to $1 \sim 4 \mathrm{mg} / \mathrm{L}$ for $\mathrm{ML}$ (HL) and $8 \sim 128 \mathrm{mg} / \mathrm{L}$ to $2 \sim 64 \mathrm{mg} / \mathrm{L}$ for the antibacterial agents, which exhibited a broad spectrum of synergistic action with aminoglycosides (amikacin, etilmicin and gentamicin), floroquinolones (levofloxacin, ciprofloxacin and norfloxacin), fosfomycin and piperacillin. The times of dilution (TOD, the extent of decreasing in MIC value) were determined up to 16 for the combined MIC. The more significant synergy after combining was determined as ML (HL) with AMK, ETM, GEN and FOS. Therefore, ML and HL showed generally the same synergistic bacteriostatic effects on the tested antibacterial agents. Moreover, ML (HL) combined with antibacterial agents did not show antagonistic effects on any of the ten MRSA strains. There were only $1 \sim 2$ strains that showed indifference.

To further evaluate the dynamic bactericidal effects of ML (HL) in combination with the antibacterial agents, the time-kill curve experiments were performed and the results are shown in Table 4 and Figs. 2 and 3. Eight of the combinations showed synergy in dynamic kill effects, with the order of potency as HL + ETM $>\mathrm{HL}+\mathrm{LEV}>\mathrm{ML}+$ $\mathrm{ETM}>\mathrm{HL}+\mathrm{AMK}>\mathrm{HL}+\mathrm{FOS}>\mathrm{HL}+\mathrm{GEN}>\mathrm{ML}+$ AMK $>$ ML + FOS. The rest of the four combinations $\mathrm{ML}+\mathrm{LEV}, \mathrm{ML}+\mathrm{CIP}, \mathrm{ML}+\mathrm{GEN}$ and HL + CIP showed additive effects (Table 4). All the combinations showed better bactericidal activity against MRSA than any of single ML (HL) or the agents at $24 \mathrm{~h}$ incubation. The bactericidal efficiency of the combinations generally lasted longer than that of the single agents (Figs. 2 and 3). The more significant combinations were determined as HL + ETM, HL + LEV and ML + ETM, with $\Delta \mathrm{LC}_{24}$ of $2.08 \sim 2.25$ (Table 4). The combinations of antibacterial agents with HL showed more significant killing effects than those with ML for a same antibacterial agent. For example, the combination of HL + LEV showed synergy but the combination of ML + LEV showed only additively. Therefore, HL is a more optimistic agent for bactericidal potentiation of the effect of conventional antibacterial agents (Table 4).

\section{Reversal of MRSA resistance to amikacin and gentamicin by $M L$ and $H L$}

Besides the synergy effectiveness, the combination of ML (HL) with amikacin (AMK) led MICs (mg/L) of AMK to decrease markedly even to reverse the MRSA resistance to AMK by the MIC Interpretive Criteria of CLSI Performance Standards, i.e. MIC $\leq 16 \mathrm{mg} / \mathrm{L}$ (susceptible), $\mathrm{MIC}=32 \mathrm{mg} / \mathrm{L}$ (intermediate), $\mathrm{MIC} \geq 64 \mathrm{mg} / \mathrm{L}$ (resistant) [47]. There is an equivalent eight strains of MRSA $(n=10)$ that showed MICs $\leq 16 \mathrm{mg} / \mathrm{L}$ against AMK when it was used in combination with ML and HL, respectively $(p<0.01)$ (Table 3 and Fig. 4). Similarly, three strains of MRSA against GEN (MIC $\leq 4 \mathrm{mg} / \mathrm{L}$ (susceptible), $\mathrm{MIC}=8 \mathrm{mg} / \mathrm{L}$ (intermediate), $\mathrm{MIC} \geq 16 \mathrm{mg} / \mathrm{L}$ (resistant)) also showed reversal interaction in combination with ML (HL) (Table 3) [47]. 
Table 3 MICs (mg/L) of magnolol $(\mathrm{ML})$ and honokiol $(\mathrm{HL})$ used alone and in combination with antibacterial agents against the ten MRSA strains

\begin{tabular}{|c|c|c|c|c|c|c|c|c|}
\hline \multirow[t]{2}{*}{ Combination $^{a}$} & \multirow[t]{2}{*}{ Effect } & \multicolumn{3}{|l|}{ MIC (mg/L) } & \multirow[t]{2}{*}{$\mathrm{FICl}^{\mathrm{C}}$} & \multicolumn{3}{|c|}{ Interaction $(n)^{d}$} \\
\hline & & Alone & Combined & $\mathrm{TOD}^{\mathrm{b}}$ & & Syn & Add & Ind \\
\hline \multirow[t]{3}{*}{$\mathrm{ML}+\mathrm{AMK}^{*}$} & Range & $8+32 \sim 32+128$ & $2+4 \sim 8+32$ & $8+16 \sim 2+2$ & $0.375 \sim 0.75$ & 8 & 2 & 0 \\
\hline & $50 \%$ & $16+64$ & $2+8$ & $4+4$ & 0.5 & & & \\
\hline & $90 \%$ & $16+64$ & $4+32$ & $4+4$ & 0.625 & & & \\
\hline \multirow[t]{3}{*}{$M L+E T M$} & Range & $8+4 \sim 32+16$ & $1+1 \sim 8+4$ & $16+8 \sim 2+4$ & $0.313 \sim 0.75$ & 8 & 2 & 0 \\
\hline & $50 \%$ & $16+8$ & $2+2$ & $4+4$ & 0.375 & & & \\
\hline & $90 \%$ & $16+16$ & $4+2$ & $2+4$ & 0.75 & & & \\
\hline \multirow[t]{3}{*}{$\mathrm{ML}+\mathrm{GEN}^{*}$} & Range & $8+16 \sim 32+128$ & $1+4 \sim 16+32$ & $16+8 \sim 1+2$ & $0.25 \sim 1.25$ & 7 & 2 & 1 \\
\hline & $50 \%$ & $16+64$ & $2+8$ & $8+4$ & 0.5 & & & \\
\hline & $90 \%$ & $16+64$ & $4+32$ & $2+2$ & 1 & & & \\
\hline \multirow[t]{3}{*}{$\mathrm{ML}+\mathrm{FOS}$} & Range & $8+128 \sim 32+256$ & $2+16 \sim 16+128$ & $8+8 \sim 2+1$ & $0.25 \sim 1.5$ & 7 & 2 & 1 \\
\hline & $50 \%$ & $16+128$ & $4+32$ & $4+8$ & 0.375 & & & \\
\hline & $90 \%$ & $16+256$ & $8+64$ & $2+4$ & 0.75 & & & \\
\hline \multirow[t]{3}{*}{$M L+C I P$} & Range & $8+256 \sim 32+512$ & $1+32 \sim 16+512$ & $16+8 \sim 2+1$ & $0.25 \sim 1.5$ & 5 & 4 & 1 \\
\hline & $50 \%$ & $16+256$ & $4+64$ & $4+8$ & 0.5 & & & \\
\hline & $90 \%$ & $16+512$ & $8+256$ & $2+2$ & 0.75 & & & \\
\hline \multirow[t]{3}{*}{$M L+L E V$} & Range & $8+128 \sim 32+256$ & $2+16 \sim 16+128$ & $8+8 \sim 1+1$ & $0.25 \sim 1.5$ & 4 & 4 & 2 \\
\hline & $50 \%$ & $16+128$ & $4+32$ & $4+8$ & 0.625 & & & \\
\hline & $90 \%$ & $16+256$ & $8+128$ & $2+2$ & 1.25 & & & \\
\hline \multirow[t]{3}{*}{$M L+N O R$} & Range & $8+128 \sim 32+256$ & $2+16 \sim 16+128$ & $8+8 \sim 1+1$ & $0.375 \sim 1.5$ & 4 & 4 & 2 \\
\hline & $50 \%$ & $16+128$ & $4+64$ & $4+4$ & 0.625 & & & \\
\hline & $90 \%$ & $16+256$ & $8+128$ & $2+2$ & 1.25 & & & \\
\hline \multirow[t]{3}{*}{$M L+P I P$} & Range & $8+128 \sim 32+256$ & $2+32 \sim 8+128$ & $4+8 \sim 2+1$ & $0.375 \sim 1.5$ & 4 & 4 & 2 \\
\hline & $50 \%$ & $16+128$ & $4+32$ & $4+4$ & 0.75 & & & \\
\hline & $90 \%$ & $16+256$ & $8+128$ & $2+1$ & 1.25 & & & \\
\hline \multirow[t]{3}{*}{$\mathrm{HL}+\mathrm{ETM}$} & Range & $8+4 \sim 16+16$ & $1+1 \sim 4+2$ & $8+8 \sim 4+4$ & $0.25 \sim 0.5$ & 10 & 0 & 0 \\
\hline & $50 \%$ & $16+8$ & $2+2$ & $8+4$ & 0.375 & & & \\
\hline & $90 \%$ & $16+16$ & $4+2$ & $4+4$ & 0.5 & & & \\
\hline \multirow[t]{3}{*}{$\mathrm{HL}+\mathrm{AMK}^{*}$} & Range & $8+32 \sim 16+128$ & $1+4 \sim 4+32$ & $8+8 \sim 4+2$ & $0.25 \sim 0.75$ & 9 & 1 & 0 \\
\hline & $50 \%$ & $16+64$ & $2+8$ & $8+4$ & 0.375 & & & \\
\hline & $90 \%$ & $16+64$ & $4+32$ & $4+4$ & 0.5 & & & \\
\hline \multirow[t]{3}{*}{$\mathrm{HL}+\mathrm{GEN}^{*}$} & Range & $8+16 \sim 16+128$ & $1+2 \sim 4+32$ & $8+8 \sim 4+2$ & $0.25 \sim 0.75$ & 8 & 2 & 0 \\
\hline & $50 \%$ & $16+64$ & $2+16$ & $8+4$ & 0.375 & & & \\
\hline & $90 \%$ & $16+64$ & $4+32$ & $4+2$ & 0.625 & & & \\
\hline \multirow[t]{3}{*}{$\mathrm{HL}+\mathrm{FOS}$} & Range & $8+128 \sim 16+256$ & $2+8 \sim 8+128$ & $8+3 \sim 21+2$ & $0.25 \sim 1.25$ & 7 & 2 & 1 \\
\hline & $50 \%$ & $16+128$ & $4+32$ & $4+4$ & 0.5 & & & \\
\hline & $90 \%$ & $16+256$ & $8+64$ & $2+2$ & 1 & & & \\
\hline \multirow[t]{3}{*}{$\mathrm{HL}+\mathrm{CIP}$} & Range & $8+256 \sim 16+512$ & $2+16 \sim 8+512$ & $8+16 \sim 2+1$ & $0.25 \sim 1.5$ & 6 & 3 & 1 \\
\hline & $50 \%$ & $16+256$ & $2+64$ & $4+4$ & 0.5 & & & \\
\hline & $90 \%$ & $16+512$ & $8+256$ & $2+2$ & 0.75 & & & \\
\hline \multirow[t]{2}{*}{$H L+L E V$} & Range & $8+128 \sim 16+256$ & $2+16 \sim 16+64$ & $8+8 \sim 1+4$ & $0.25 \sim 1.25$ & 5 & 4 & 1 \\
\hline & $50 \%$ & $16+128$ & $4+32$ & $4+8$ & 0.5 & & & \\
\hline
\end{tabular}


Table 3 MICs (mg/L) of magnolol $(\mathrm{ML})$ and honokiol $(\mathrm{HL})$ used alone and in combination with antibacterial agents against the ten MRSA strains (Continued)

\begin{tabular}{|c|c|c|c|c|c|c|c|c|}
\hline & $90 \%$ & $16+256$ & $8+32$ & $2+4$ & 1.125 & & & \\
\hline \multirow[t]{3}{*}{$\mathrm{HL}+\mathrm{PIP}$} & Range & $8+128 \sim 16+256$ & $1+16 \sim 16+128$ & $8+8 \sim 1+1$ & $0.25 \sim 1.5$ & 5 & 3 & 2 \\
\hline & $50 \%$ & $16+128$ & $2+32$ & $8+4$ & 0.5 & & & \\
\hline & $90 \%$ & $16+256$ & $8+128$ & $2+2$ & 1.25 & & & \\
\hline \multirow[t]{3}{*}{$\mathrm{HL}+\mathrm{NOR}$} & Range & $8+128 \sim 16+256$ & $1+16 \sim 8+256$ & $8+8 \sim 1+1$ & $0.25 \sim 1.5$ & 3 & 5 & 2 \\
\hline & $50 \%$ & $16+128$ & $4+64$ & $4+4$ & 0.75 & & & \\
\hline & $90 \%$ & $16+256$ & $8+128$ & $2+2$ & 1.25 & & & \\
\hline
\end{tabular}

${ }^{a} M L$ Magnolol, HL Honokiol, AMK Amikacin, FOS Fosfomycin, LEV Levofloxacin, ETM Etilmicin, PIP Piperacillin, CIP Ciprofloxacin, NOR Norfloxacin, All data on the left side of " + " belong to $\mathrm{ML}$ or $\mathrm{HL}$, and the data on the right side of " + " belong to the conventional antibacterial agents, for example, "ML $+\mathrm{AMK}$ " means $\mathrm{ML}$ combined with AMK. ${ }^{\mathrm{b}} \mathrm{TOD}$ Times of dilution $=\mathrm{MIC}_{\mathrm{Alone}} / \mathrm{MIC}_{\mathrm{Combined}}$, ranged from the maximum to the minimum. ${ }^{\mathrm{C}} \mathrm{FICl}$ Fractional inhibitory concentration index, ${ }^{\mathrm{d}}$ Add Additivity $(0.5<\mathrm{FICl} \leq 1)$, Ind Indifference $(1<\mathrm{FICl} \leq 2)$, Syn Synergy $(\mathrm{FICl} \leq 0.5)$. $n^{\prime}$ Number of MRSA strains which showed the interactions. The total number is $n=10$, e.g. $n=\mathrm{n}^{\prime}(\mathrm{s})+\mathrm{n}^{\prime}(\mathrm{a})=8+2$ for $\mathrm{ML}+\mathrm{AMK}$ combination in the first line in the table. ${ }^{*}$ No statistically significant differences among the combinations of $\mathrm{ML}+\mathrm{AMK}, \mathrm{ML}+\mathrm{GEN}, \mathrm{HL}+\mathrm{AMK}$ and $\mathrm{HL}+\mathrm{GEN}(p>0.01)$

\section{Discussion}

In the present report, we performed the antibacterial evaluations of ML and HL against MRSA both used alone and in combination with clinical conventional antibacterial agents of broad classes. The synergism of ML and HL on MRSA is found for the first time so far to the best of our knowledge [37, 39]. We determined the antibacterial activity of ML and $\mathrm{HL}$ against MRSA alone with $\mathrm{MIC}_{50} / \mathrm{MBC}_{50}(n=10)$ of $16 \sim 64 \mathrm{mg} / \mathrm{L}$ which are similar to the results of the previous report which showed MIC/MBC of $12.5 / 25 \mathrm{mg} / \mathrm{L}$ [37]. The difference is reasonable for the varied MRSA strains

Table 4 Collected time-killing assay results of various combinations of $\mathrm{ML}$ and $\mathrm{HL}$ with antibacterial agents at $24 \mathrm{~h}$ incubation against a clinical MRSA144 strain

\begin{tabular}{lll}
\hline Combination $^{a}$ & Masc $^{b}$ & $\Delta$ LC $_{24}(\text { Int })^{c}$ \\
\hline$H L+$ ETM & ETM & $2.25 \pm 0.12$ (Syn) \\
$H L+$ LEV & HL & $2.09 \pm 0.09$ (Syn) $^{*}$ \\
$M L+$ ETM & ETM & $2.08 \pm 0.1$ (Syn) \\
$H L+$ AMK & AMK( ML) & $2.05 \pm 0.07($ Syn) \\
$H L+$ FOS & FOS & $2.04 \pm 0.03$ (Syn) \\
$H L+$ GEN & HL & $2.02 \pm 0.01$ (Syn) \\
$M L+$ AMK & AMK( ML) & $2.02 \pm 0.02$ (Syn) \\
$M L+$ FOS & FOS( ML) & $2.00 \pm 0.01$ (Add) \\
$M L+$ LEV & LEV(=ML) & $1.64 \pm 0.04$ (Add) \\
$M L+$ CIP & CIP & $1.24 \pm 0.05$ (Add) \\
$M L+$ GEN & GEN & $1.24 \pm 0.03$ (Add) \\
$H L+$ CIP & HL & $1.06 \pm 0.04$ (Add) \\
\hline
\end{tabular}

${ }^{a}$ SAL Salvianolate, AMP Ampicillin, CAZ Ceftazidime, CFZ Cefazolin, CPS Cefoperazone-sulbactam, PTZ Piperacillin-tazobactam, AMK Amikacin, CLI Clindamycin, ERY Erythromycin, FOS Fosfomycin, LEV Levofloxacin ${ }^{\mathrm{b}}$ Masc Most active single drug

${ }^{\mathrm{c}} \Delta L \mathrm{C}_{24} \Delta \mathrm{Log}_{10} \mathrm{CFU} / \mathrm{mL}$ at $24 \mathrm{~h}$, Int Interaction, Syn Synergy $\left(\Delta \mathrm{LC}_{24} \geq 2\right)$, Add Additivity $\left(1<\Delta \mathrm{LC}_{24}<2\right)$, Ind Indifference $\left(\Delta \mathrm{LC} \mathrm{C}_{24}= \pm 1\right)$. Data are expressed as the mean \pm standard error. ${ }^{*} p<0.05$ used. From the results of combinatory effect on MRSA and the reported antifungal synergism [39], the two compounds are demonstrated to possess a wide spectrum of antimicrobial potentiation of conventional chemotherapy. It would be beneficial for the treatment of mixed infections and even the co-infection of tumor diseases, considering ML (HL) also potentiating antitumor agents [41-46].

It is important and valuable of ML and HL that potentiate the antimicrobial activity of aminoglycosides and other antibacterial drugs against MRSA, which could prevent the drugs from development of MDR to the troublesome germ. As aminoglycosides are one class of the important antimicrobials for the treatment of infectious diseases, the MRSA resistance reversal effects of ML and HL to the aminoglycosides agents (AMK, ETM and GEN) are especially significant for their application with largely reducing toxic reactions of the hosts' liver, kidney and neural system by a substantially lowered dosage. Hence, greater sample scales are needed in order to draw a more reliable significance of the effectiveness on MRSA from clinical specimens and antibiotics.

The mechanism of the action of ML and HL against MRSA together with their synergism with antibacterial agents is still an unmet question. Two previous reviews summarized four main resistance mechanisms from bacteria: (i) receptor or active site modification, (ii) enzymatic degradation or modification of antibiotic, (iii) decreased penetration, or (iv) increased efflux $[9,10]$. It was reported that the antimicrobial mechanisms of Magnolia officinalis extract resulted mainly in cell membrane and wall damage, causing increased permeability of cell membranes or lysis of cell walls and loss of cellular constituents, impairment of structural components and changes in bacterial cell morphology [21], which could ascribed to ML and HL, the two main constituents of the plant. Some studies also have demonstrated that increased permeability of 


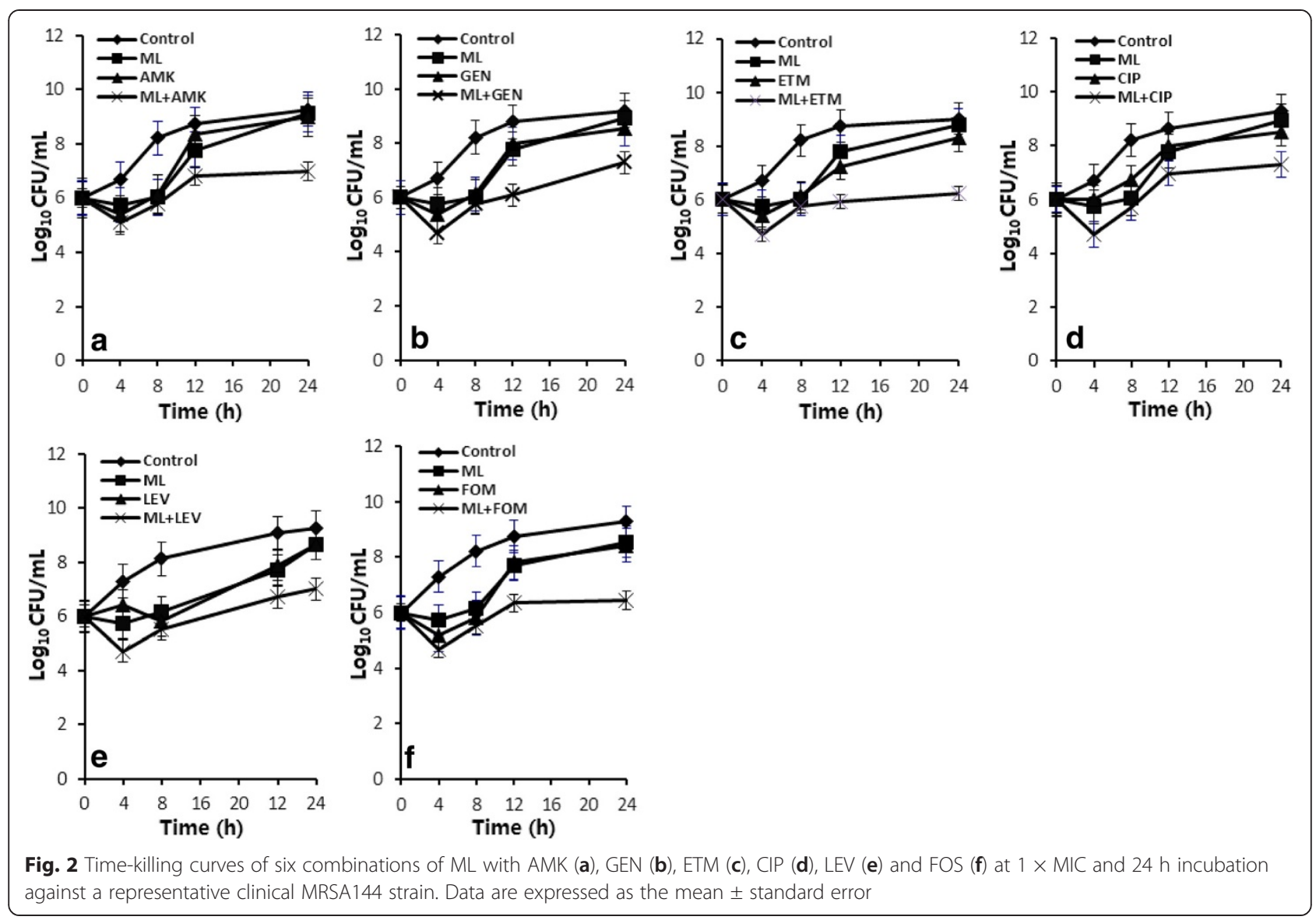

the bacterial plasma membrane plays an important role in modulating resistance to aminoglycoside $[57,58]$. Another study showed a phenolic diterpene totarol inhibits multidrug efflux pump activity in Staphylococcus aureus [59]. Therefore, the agents in the present report which shows the resistance reversal effects on the aminoglycosides (AMK and GEN) or synergistic potentiation of other conventional drugs could be through these mechanisms to a certain degree, though the real mechanism is remained to be clarified.

There are additional evidences revealing ML and HL as the modulators of the microbial membrane permeability. The two compounds showed active to extremely broad pathogenic microbial species. Apart from MSSA and MRSA, they showed as well antimicrobial activities against many other bacteria [19-31] and fungi [32-34] species and even exhibited antiviral [35] and nemicidal [36] activities. This antimicrobial mode is suggested like the antibacterial compounds of surface-active types which share the characters of usually nonselective to bacteria and very close MIC/MBC concentrations [30]. Therefore, ML and HL very likely target the extra cytoplasmic region as a nonionic surfactant and thus does not need to enter the cell, thereby avoiding most cellular pump-based resistance mechanisms as previously proposed [30].
The effects of ML (HL) on MRSA present here will expand the knowledge of their antimicrobial action and the future direction of anti-MDR investigations for drug development.

\section{Conclusions}

ML and HL showed a broad spectrum of synergistic potentiation of conventional antibacterial agents, especially the resistance reversal of AMK and GEN against clinical MRSA isolates. These in vitro activities of ML and HL might partly ascribe to modulate the bacterial cell membrane penetration and warrant further pharmacological investigation.

\section{Ethics statement}

The study was conducted in compliance with the ethics principles of the Declaration of Helsinki and Good Clinical Practice and China regulatory requirements. The study protocol (RCNM0116) was approved 10 June 2011 by the Ethics Committee and health authorities of Kunming General Hospital (KGH). Written informed consent was obtained from all subjects prior to sample commencement. 

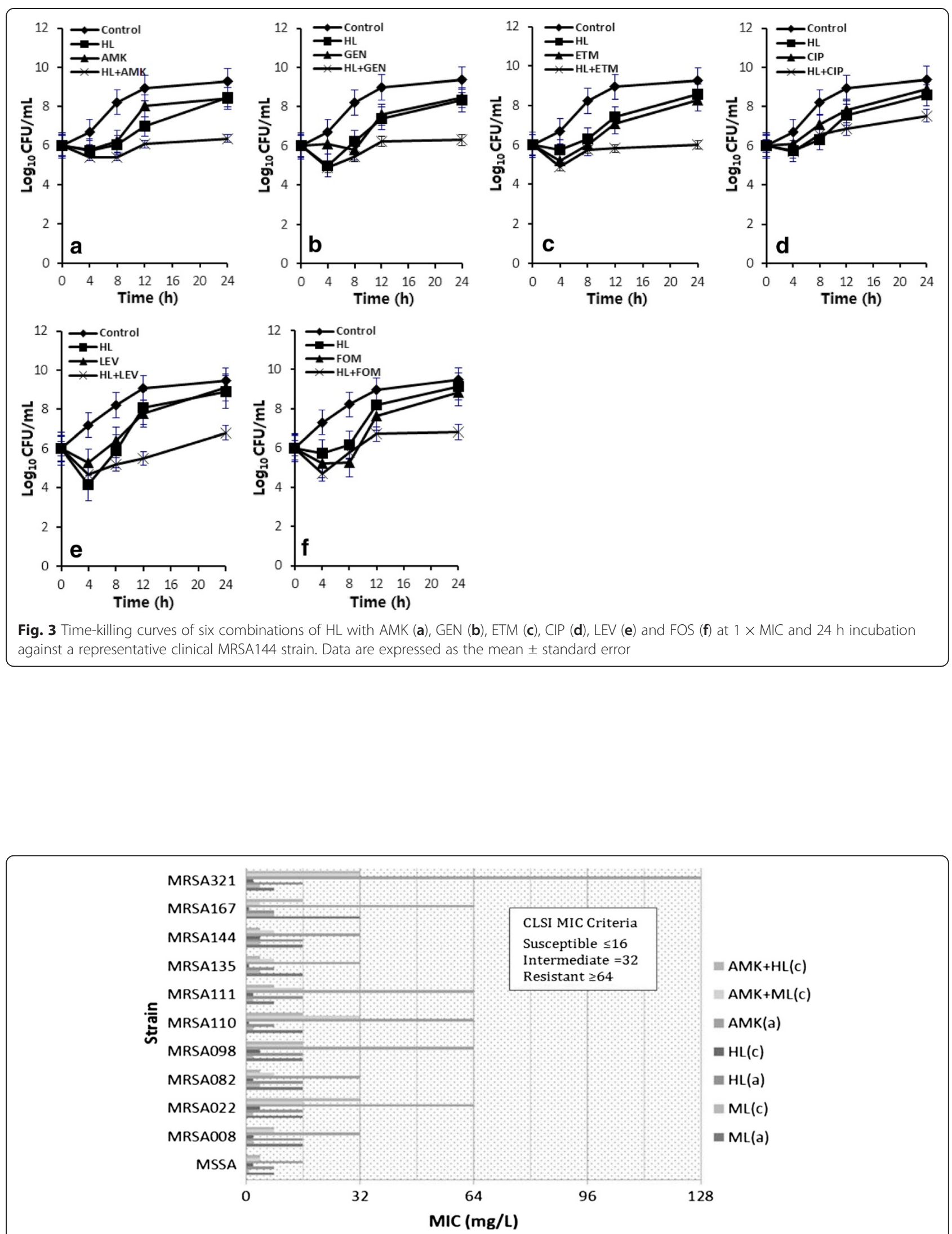

Fig. 4 Reversal of MRSA resistance to AMK when it was used with combination with $M L^{*}$ and $H L^{*}$, respectively $\left({ }^{*} p>0.01\right.$; a: alone; c: combined) 


\section{Competing interests}

The authors declare that they have no competing interests.

\section{Authors' contributions}

GY-Z and JH wrote the paper. GY-Z and XJ-Z conceived the study and performed the experiments. JH and YQ-L participate in the data analyses. GC-W contributed to materials/technical support. All authors read and approved the final manuscript.

\section{Acknowledgements}

This work was supported by the National Natural Science Foundation of China (NSFC 81173504) and the supporting fund of Yunnan Province of China (2008PY001).

\section{Author details}

${ }^{1}$ Research Center for Natural Medicines, Kunming General Hospital of Chengdu Military Command, Kunming 650032, China. ${ }^{2}$ School of Pharmacy, Kunming Medical University, Kunming 650032, China. ${ }^{3}$ School of Basic Medical Sciences, Yunnan Traditional Chinese Medical College, Kunming 650500, China.

Received: 3 June 2015 Accepted: 17 November 2015 Published online: 01 December 2015

\section{References}

1. Pantosti A, Venditti M. What is MRSA? Eur Respir J. 2009;34:1190-6.

2. Jevons MP. "Celbenin"-resistant staphylococci. Br Med J. 1961;124:124-5.

3. Stefani S, Chung DR, Lindsay JA, Friedrich AW, Kearns AM, Westh $\mathrm{H}$, et al. Meticillin-resistant Staphylococcus aureus (MRSA): global epidemiology and harmonisation of typing methods. Int J Antimicrob Agents. 2012;39:273-82

4. Chang S, Sievert DM, Hageman JC, Boulton ML, Tenover FC, Downes FP, et al. Infection with vancomycin-resistant Staphylococcus aureus containing the vanA resistance gene. N Engl J Med. 2003;348:1342-7.

5. Freire-Moran L, Aronsson B, Manz C, Inge C, Gyssens IC, So AD, et al. Critical shortage of new antibiotics in development against multidrug-resistant bacteria-Time to react is now. Drug Resist Update. 2011;14:118-24.

6. Gibbons S. Anti-staphylococcal plant natural products. Nat Prod Rep. 2004;21:263-72.

7. Gibbons S. Phytochemicals for bacterial resistance - strengths, weaknesses and opportunities. Planta Med. 2008;74:594-602.

8. Saleem M, Nazir M, Ali MS, Hussain H, Lee YS, Riaz N, et al. Antimicrobial natural products: an update on future antibiotic drug candidates. Nat Prod Rep. 2010;27:238-54.

9. Hemaiswarya S, Kruthiventi AK, Doble M. Synergism between natural products and antibiotics against infectious diseases. Phytomedicine. 2008;15:639-52.

10. Wagner H, Ulrich-Merzenich G. Synergy research: Approaching a new generation of phytopharmaceuticals. Phytomedicine. 2009;16:97-110.

11. Zuo GY, Zhang XJ, Yang CX, Han J, Wang GC, Bian ZQ. Evaluation of traditional Chinese medicinal plants for anti-MRSA activity with reference to the treatment record of infectious diseases. Molecules. 2012;17:2955-67.

12. Zuo GY, Han ZQ, Hao XY, Han J, Li ZS, Wang GC. Synergy of aminoglycoside antibiotics by 3-Benzylchroman derivatives from the Chinese drug Caesalpinia sappan against clinical methicillin-resistant Staphylococcus aureus (MRSA). Phytomedicine. 2014;21:936-41.

13. Zuo GY, An J, Han J, Zhang YL, Wang GC, Hao XY, et al. Isojacareubin from the Chinese herb Hypericum japonicum with antibacterial and antibiotic synergy effects on clinical methicillin-resistant Staphylococcus aureus (MRSA). Int J Mol Sci. 2012;13:8210-8.

14. Nanjing University of Traditional Chinese Medicine (NUTCM). Dictionary of Chinese crude drugs. 2nd ed. Shanghai, China: Shanghai Scientific Technologic Publisher; 2005. p. 2282-6.

15. Zhang SJ, Zhong LY. Advances in the chemical composition and modern pharmacological research of Magnolia officinalis. J Chin Med Materia. 2013;36:838-43.

16. Chinese Pharmacopoeia Commission. Chinese pharmacopoeia (I). Beijing, China: Chemical Industry Press; 2010. p. 235.

17. Yu SX, Yan RY, Liang RX, Wang W, Yang B. Bioactive polar compounds from stem bark of Magnolia officinalis. Fitoterapia. 2012;83:356-61.

18. Shen J, Man K, Huang P, Chen W, Chen D, Cheng Y, et al. Honokiol and magnolol as multifunctional antioxidative molecules for dermatologic disorders. Molecules. 2010;15:6452-65.
19. Liao YS. Studies on the antibacterial actions of Huang-lien and Hou-p'o. Part I. The antibacterial actions of Huang-lien and Hou-p'o in vitro. Acta Phamaceutica Sinica. 1954;2:5-10.

20. Liao YS. Studies on the antibacterial actions of Huang-lien and Hou-p'o. Part II. The anti-Bacillus anthracis action of Huang-lien and Hou-p'o in Guinea pig. Acta Phamaceutica Sinica. 1954;2:11-6.

21. Hu YJ, Qiao JL, Zhang X, Ge CR. Antimicrobial effect of Magnolia officinalis extract against Staphylococcus aureus. J Sci Food Agric. 2011;91:1050-6.

22. Namba T, Tsunezuka M, Hattori M. Dental caries prevention by traditional Chinese medicines. Part II. Potent antibacterial action of Magnoliae cortex extracts against Streptococcus mutans. Planta Med. 1982;44:100-6.

23. Bae K, Yoo B, Lee M, Seo W. Antimicrobial activities of hydroxybiphenyl derivatives (I). Arch Pharm Res. 1985;8:85-9.

24. Seo W, Koo S, Bae K. Antimicrobial activities of hydroxybiphenyl derivatives (II). Arch Pharm Res. 1986;9:127-30.

25. Nitao JK, Nair MG, Thorogoo DL, Johnson KSJ, Scriber M. Bioactive neolignans from the leaves of Magnolia virginiana. Phytochemistry. 1991;30:2193-5.

26. Chang BS, Lee YM, Ku Y, Bae KH, Chung CP. Antimicrobial activity of magnolol and honokiol against periodontopathic microorganisms. Planta Med. 1998;64:367-9.

27. Ho K, Tsai C, Chen C, Huang J, Lin C. Antimicrobial activity of honokiol and magnolol isolated from Magnolia officinalis. Phytother Res. 2001;15:139-41.

28. Park J, Lee J, Jung E, Park Y, Kim K, Park B, et al. In vitro antibacterial and anti-inflammatory effects of honokiol and magnolol against Propionibacterium sp. Europ J Pharm. 2004;496:189-95.

29. Greenberg M, Urnezis P, Tian MM. Compressed mints and chewing gum containing Magnolia bark extract are effective against bacteria responsible for oral malodor. J Agric Food Chem. 2007;55:9465-9.

30. Greenberg M, Dodds M, Minmin Tian MM. Naturally occurring phenolic antibacterial compounds show effectiveness against oral bacteria by a quantitative structure-activity relationship study. J Agric Food Chem. 2008;56:11151-6.

31. Kim YS, Lee JY, Park J, Hwang W, Lee J, Park D. Synthesis and microbiological evaluation of honokiol derivatives as new antimicrobial agents. Arch Pharm Res. 2010;33:61-5.

32. Mori M, Aoyama M, SDoi S. Antifungal constituents in the bark of Magnolia obovata Thunb. Holz als Roh-und Werkstoff. 1997;55:275-8.

33. Bang KH, Kim YK, Min BS, Na MK, Rhee YH, Lee JP, et al. Antifungal activity of magnolol and honokiol. Arch Pharm Res. 2000;23:46-9.

34. Choi NH, Choi GJ, Min BS, Jang KS, Choi YH, Kang MS, et al. Effects of neolignans from the stem bark of Magnolia obovata on plant pathogenic fungi. J Appl Microb. 2009;106:2057-63.

35. Amblard F, Govindarajan B, Lefkove B, Rapp KL, Detorio M, Arbiser JL, et al. Synthesis, cytotoxicity, and antiviral activities of new neolignans related to honokiol and magnolol. Bioorg Med Chem Lett. 2007;17:4428-31.

36. Li GH, Dang LI, Hong L, Zheng LJ, Liu FF, Li L, et al. Nematicidal activity of honokiol and magnolol isolated from Magnolia tripetala. J Phytopath. 2009;157:390-2.

37. Syu WJ, Shen CC, Lu JJ, Lee GH, Sun CM. Antimicrobial and cytotoxic activities of neolignans from Magnolia officinalis. Chem Biodiversity. 2004;1:530-7.

38. Jada S, Reddy Doma M, Singh PP, Kumar S, Malik F, Sharma A, et al. Design and synthesis of novel magnolol derivatives as potential antimicrobial and antiproliferative compounds. Europ J Med Chem. 2012;51:35-41.

39. Jin J, Guo N, Zhang J, Ding Y, Tang X, Liang J, et al. The synergy of honokiol and fluconazole against clinical isolates of azole-resistant Candida albicans. Lett Appl Microbiol. 2010;51:351-7.

40. Bae K, Oh H. Synergistic effect of lysozyme on bactericidal activity of magnolol and honokiol against a cariogenic bacterium, Streptococcus mutans OMZ 176. Arch Pharm Res. 1990;13:117-9.

41. Liu Y, Chen L, He X, Fan L, Yang G, Chen X, et al. Enhancement of therapeutic effectiveness bycombining liposomal honokiol with cisplatin in ovarian carcinoma. Int J Gynecol Cancer. 2008;18:652-9.

42. Liu H, Zang C, Emde A, Planas-Silva MD, Rosche M, Kühnl A, et al. Anti-tumor effect of honokiol alone and in combination with other anti-cancer agents in breast cancer. Europ J Pharmacol. 2008:591:43-51.

43. Hou W, Chen L, Yang G, Zhou H, Jiang Q, Zhong Z, et al. Synergistic antitumor effects of liposomal honokiol combined with adriamycin in breast cancer models. Phytother Res. 2008;22:1125-32.

44. Arora S, Bhardwaj A, Srivastava SK, Singh S, McClellan S, Wang B, et al. Honokiol arrests cell cycle, induces apoptosis, and potentiates the cytotoxic effect of gemcitabine in human pancreatic cancer cells. PLOS ONE. 2011;6:e21573. doi:10.1371/journal.pone.0021573. 
45. Wang X, Beitler JJ, Wang H, Lee MJ, Huang W, Koenig L, et al. Honokiol enhances paclitaxel efficacy in multi-drug resistant human cancer model through the induction of apoptosis. PLOS ONE. 2014;9:e86369. doi:10.1371/journal.pone.0086369.

46. Arora S, Singh S, Piazza GA, Contreras CM, Panyam J, Singh AP. Honokiol: a novel natural agent for cancer prevention and therapy. Curr Mol Med. 2012;12:1244-52.

47. Clinical Laboratory Standards Institute. Table 2C. Zone diameter and MIC interpretive standards for staphylococcus spp. In: Performance standards for antimicrobial susceptibility testing; twenty-second informational supplement. Approved standard. Wayne, PA, USA: CLSI; 2012. p. M100-S22.

48. Zhang K, McClure JA, Elsayed S, Louie T, Conly JM. Novel multiplex PCR assay for characterization and concomitant subtyping of staphylococcal cassette chromosome mec types I toV in methicillin-resistant Staphylococcus aureus. J Clin Microbiol. 2005;43:5026-33.

49. Clinical Laboratory Standards Institute. Performance standards for antimicrobial disk susceptibility tests. Approved standard, 9th ed. Document M2-A9. Wayne, PA, USA: CLSI; 2006.

50. Akcam FZ, Tinaz GB, Kaya O, Tigli A, Ture E, Hosoglu S. Evaluation of methicillin resistance by cefoxitin disk diffusion and PBP2a latex agglutination test in mecA-positive Staphylococcus aureus, and comparison of mecA with femA, femB, femX positivities. Microbiol Res. 2009;164:400-3.

51. Clinical Laboratory Standards Institute. Approved standard M100-S17. PA, USA.: CLSI, Wayne; 2007. Performance Standards for Antimicrobial Susceptibility Testing-17th Informational Supplement.

52. Clinical Laboratory Standards Institute. Approved standard M7-A7. PA, USA. CLSI, Wayne; 2006. Methods for Dilution Antimicrobial Susceptibility Tests for Bacteria that Grow Aerobically, 7th ed.

53. Clinical Laboratory Standards Institute. Methods for determining bactericidal activity antimicrobial agents. Wayne, PA, USA: Approved Guidelines. Document M26-A. CLSI (formerly NCCLS); 1999.

54. Hu ZQ, Zhao WH, Asano N, Yoda Y, Hara Y. Epigallocatechin gallate synergistically enhances the activity of carbapenems against methicillin resistant Staphylococcus aureus. Antimicrob Agents Chemother. 2002;46:558-60.

55. Orhan G, Bayram A, Zer Y, Balci I. Synergy tests by E test and checkerboard methods of antimicrobial combinations against Brucella melitensis. J Clin Microbiol. 2005;43:140-3.

56. Chin JN, Jones RN, Sader HS, Savage PB, Rybak MJ. Potential synergy activity of the novel ceragenin, CAS-13, against clinical isolates of Pseudomonas aeruginosa, including multidrug-resistant $P$. aeruginosa. J Antimicrob Chemother. 2008;61:365-70.

57. Kim ES, Jeong SI, Kim JH, Park C, Kim SM, Kim JK, et al. Synergistic effects of the combination of 20-hydroxyecdysone with ampicillin and gentamicin against methicillin-resistant Staphylococcus aureus. J Microbiol Biotechnol. 2009;19:1576-81.

58. Mates SM, Eisenberg ES, Mandel LJ, Patel L, Kaback HR, Miller MH. Membrane potential and gentamicin uptake in Staphylococcus aureus. Proc Natl Acad Sci U S A. 1982;79:6693-7.

59. Smith ECJ, Kaatz GW, Seo SM, Wareham N, Williamson EM, Gibbons S. The phenolic diterpene totarol inhibits multidrug efflux pump activity in Staphylococcus aureus. Antimicro Agents Chemother. 2007;51:4480-3.

\section{Submit your next manuscript to BioMed Central and we will help you at every step:}

- We accept pre-submission inquiries

- Our selector tool helps you to find the most relevant journal

- We provide round the clock customer support

- Convenient online submission

- Thorough peer review

- Inclusion in PubMed and all major indexing services

- Maximum visibility for your research

Submit your manuscript at www.biomedcentral.com/submit
(O) BioMed Central 